\title{
O JOGO DIDÁTICO COMO INSTRUMENTO PARA EDUCAÇÃO AMBIENTAL NAS SÉRIES FINAIS DO ENSINO FUNDAMENTAL: PROPOSTA PARA TRABALHAR OS TEMAS DIVERSIDADE DA VIDA NOS AMBIENTES E DIVERSIDADE DOS MATERIAIS
}

Alexandre de Faria Silva ${ }^{1}$

Resumo: O presente artigo aponta a importância do uso de jogos como instrumento para Educação Ambiental na escola, de modo a despertar a consciência ecológica dos alunos, fazendo-os reconhecer a si próprios como parte integrante e responsável para a conservação e preservação do meio ambiente. Após a aplicação de um jogo didático, onde foram trabalhados os temas Diversidade da Vida nos Ambientes e Diversidade dos Materiais, o mesmo foi avaliado por alunos das séries finais do ensino fundamental de uma escola pública estadual. Os resultados indicaram que eles compreenderam e se familiarizaram com questões e problemas ambientais, sendo estimulados a adquirir conhecimentos e adotar novas formas de conduta para proteger e melhorar o meio ambiente.

Palavras-chave: Jogos Didáticos; Educação Ambiental; Ludicidade; Aprendizagem.

1'Licenciatura em Ciências Biológicas pela Universidade de Itaúna. Pós-graduando em Gestão Pública e Controle com Foco em Resultados pela Escola de Contas e Capacitação Professor Pedro Aleixo (Tribunal de Contas do Estado de Minas Gerais - TCEMG). Pós-graduando em Ciências Biológicas pela Universidade Federal de Juiz de Fora (UFJF). E-mail: alexandre2789@yahoo.com.br 


\section{Introdução}

Historicamente, a humanidade demonstra pouco ou nenhum cuidado com o planeta e com os seres que nele vivem. Desde que a Terra passou a ser habitada por uma espécie denominada Homo sapiens, espécime capaz de modificar o meio ambiente, inúmeras mudanças para a natureza foram se desencadeando, muitas delas, negativas.

Tendo em vista a ação devastadora do ser humano no Planeta, agravada pelo consumismo desenfreado e o consequente desrespeito ao meio ambiente, é fundamental trabalhar a Educação Ambiental na escola, pois, considerando a importância da temática ambiental e a visão integrada do mundo, no tempo e no espaço, sobressaem-se as escolas como espaços privilegiados na implementação de atividades que levem a interações construtivas, justas e ambientalmente sustentáveis.

$\mathrm{Na}$ expectativa de superar problemas que afligem a educação, a implementação de práticas educativas inovadoras, dentre as quais se destaca o uso de metodologias e estratégias de ensino diversificadas e contextualizadas pode contribuir significativamente.

Diante da infinidade de estratégias para a abordagem de temas científicos, foi construído um jogo didático como proposta para auxiliar os professores de Ciências no trabalho relacionado à Educação Ambiental.

O presente trabalho teve como objetivos a elaboração, construção e avaliação de um jogo didático de tabuleiro direcionado para a sensibilização, compreensão e posicionamento dos alunos frente às questões ambientais. Pretende-se desenvolver a consciência ambiental dos alunos e fazê-los adotar postura na escola, em casa e em sua comunidade que os levem a interações construtivas, justas e ambientalmente sustentáveis. Participaram da atividade alunos das séries finais do ensino fundamental ( $3^{\circ}$ e $4^{\circ}$ ciclos) da rede pública estadual de ensino de Igaratinga-MG.

\section{Fundamentação teórica e algumas considerações}

Notoriamente, as atividades lúdicas fornecem um ambiente agradável, motivador, prazeroso, planejado e enriquecido, que possibilita o aprendizado e o desenvolvimento de várias habilidades. Acrescenta-se a isso, a possibilidade de utilizar jogos didáticos, de modo a auxiliar os alunos na construção do conhecimento em qualquer área (PEDROSO, 2009).

As atividades lúdicas permitem desenvolver e aprimorar capacidades, explorar e refletir sobre a realidade, incorporar, e, ao mesmo tempo, questionar regras e papéis sociais. Ao utilizar brincadeiras, jogos e brinquedos na prática pedagógica, é possível ampliar e enriquecer a rede de significados construtivos, tanto para crianças como para os jovens (MALUF, 2006). 
$\mathrm{Na}$ literatura referente à área da Educação, e, mais especificamente, àquela destinada ao Ensino, é possível encontrar uma ampla variedade de opiniões em defesa do uso de jogos na aprendizagem.

Os jogos e brincadeiras são elementos muito valiosos no processo de apropriação do conhecimento. Permitem o desenvolvimento de competências no âmbito da comunicação, das relações interpessoais, da liderança e do trabalho em equipe, utilizando a relação entre cooperação e competição em um contexto formativo. O jogo oferece o estímulo e o ambiente propícios que favorecem o desenvolvimento espontâneo e criativo dos alunos e permite ao professor ampliar seu conhecimento de técnicas ativas de ensino, desenvolver capacidades pessoais e profissionais para estimular nos alunos a capacidade de comunicação e expressão, mostrando-lhes uma nova maneira, lúdica, prazerosa e participativa de relacionar-se com o conteúdo escolar, levando a uma maior apropriação dos conhecimentos envolvidos (BRASIL, 2002, p.56).

O jogo oferece o estímulo e o ambiente propícios que favorecem o desenvolvimento espontâneo e criativo dos alunos e permite ao professor ampliar seu conhecimento de técnicas ativas de ensino, desenvolver capacidades pessoais e profissionais para estimular nos alunos a capacidade de comunicação e expressão, mostrando-lhes uma nova maneira, lúdica, prazerosa e participativa de relacionar-se com o conteúdo escolar, levando a uma maior apropriação dos conhecimentos envolvidos (BRASIL, 2002, p.56).

[...] por aliar os aspectos lúdicos aos cognitivos, entendemos que o jogo é uma importante estratégia para o ensino e a aprendizagem de conceitos abstratos e complexos, favorecendo a motivação interna, o raciocínio, a argumentação, a interação entre alunos e entre professores e alunos. (CAMPOS, BORTOLOTO E FELICIO, 2003, p.59)

Segundo Kishimoto (1996), quando o objetivo é a apropriação de conhecimentos por parte do aluno, o professor deve utilizar propostas pedagógicas que atuem nos componentes internos da aprendizagem. Ainda segundo essa autora, o jogo conduz a um conteúdo didático especifico resultando em um empréstimo da ação lúdica para a compreensão de informações.

Para Fortuna (2003), o ato de jogar desenvolve no aluno a iniciativa, a imaginação, o raciocínio, a memória, a atenção, a curiosidade e o interesse, permitindo que ele se concentre por longo tempo em uma atividade. 
Considerando que o jogo aparece em todas as idades, e se constitui em atividade presente na experiência de vida do homem, deve ser integrado às atividades escolares não sob o aspecto de complementaridade, mas como trabalho educativo que possibilita descobrir, superar desafios, investigar e questionar (MARCELLINO, 1989).

O jogo didático é aquele fabricado com o intuito de proporcionar determinadas aprendizagens, diferenciando-se do material pedagógico por contemplar o aspecto lúdico (CUNHA, 1988).

Para o aluno o jogo constitui um fim, pois ele participa com o objetivo de obter prazer. Para os educadores que utilizam o jogo com o objetivo de ensinar, este é visto como um meio capaz de transmitir uma mensagem educacional (DOHME, 2003).

Entretanto, a utilização de jogos nem sempre foi vista como uma ferramenta didática pertinente no processo de ensino e aprendizagem, pois, uma vez que a ideia de jogo se encontra intimamente associada ao prazer, ele era visto como algo de pouca importância para a formação da criança. Por isso, a utilização do jogo demorou a ser aceita no ambiente educacional (GOMES; FRIEDRICH, 2001).

Segundo Miranda (2001), o jogo didático permite o alcance de objetivos no campo da cognição (ato ou processo de desenvolvimento da inteligência e da personalidade, essenciais para a construção do conhecimento); afeição (desenvolvimento da sensibilidade/estima e atuação no sentido de estreitar relações de amizade e afetividade); socialização (simulação da vida coletiva); motivação (envolvimento da ação, empenho e mobilização da curiosidade) e criatividade.

Um jogo que explora o trabalho em grupo possibilita que cada um de seus membros aprenda a integrar-se em um coletivo, a compartilhar ocupações, a exercer responsabilidades, a coordenar esforços e a encontrar alternativas para solucionar problemas, assim, é possível a troca e a construção intelectual para todos (SANMARTí, 2002).

Para Campos et al. (2003), a apropriação e a aprendizagem significativa de conhecimentos são facilitadas quando se propõe uma atividade lúdica, pois os alunos ficam entusiasmados e interessados quando recebem a proposta de aprender de uma forma mais motivadora e divertida. Ainda segundo essa autora, o jogo ganha amplitude como instrumento ideal da aprendizagem, na medida em que instiga e provoca estímulo ao interesse do aluno, ajuda a construir seu próprio conhecimento, desenvolve e enriquece sua personalidade, e representa uma ferramenta pedagógica que leva o professor à condição de condutor, motivador e avaliador da aprendizagem.

Neste sentido, ao considerar o desenvolvimento e a sistematização do trabalho escolar voltado para a Educação Ambiental autores como Marpica e Logarezzi (2010, p.116) enfatizam que: 
A educação, particularmente nas práticas pedagógicas escolares, pode ser vista como um processo importante para transformações da realidade que conduzam a um mundo socialmente mais justo e ambientalmente mais sustentável. Para tanto, entre as escolhas que devem marcar o trabalho escolar, destaca-se a necessidade, cada vez mais imperativa, de incorporação da dimensão ambiental em suas práticas, especialmente no processo de ensino e aprendizagem.

Atualmente, em decorrência das constantes e progressivas alterações que a natureza vem sofrendo, nota-se que as questões ambientais são amplamente discutidas. No âmbito educacional, sob a égide da Educação Ambiental, o trabalho direciona-se fundamentalmente para a preservação da natureza, em especial a dos recursos que ela disponibiliza para o homem (ARNONI et al., 2006). Neste contexto, para cumprir plenamente a sua função social, a escola deve contribuir para a socialização dos conhecimentos científicos, fazendo-se necessário que os principais temas discutidos e valorizados pela sociedade estejam sistematizados como saber escolar (SILVA; CARVALHO, 2002).

Nas discussões sobre Educação Ambiental, a instituição escolar parece ser um lugar privilegiado. Para legitimar essa afirmação recorre-se a REIGOTA (1998) e GUIMARÃES (2000) que enfatizam a importância da escola, de modo geral, na abordagem e discussão de questões da atualidade:

A escola tem sido historicamente o espaço indicado para a discussão e o aprendizado de vários temas urgentes e de atualidade, como resultado da sua importância na formação dos cidadãos. Evidentemente que a escola deve estar sempre aberta ao conhecimento, inquietações e propostas de sua época, e procurar consolidar inovações pedagógicas que contribuam para que a mesma continue cumprindo com seu papel social. (REIGOTA, 1998, p.47)

A Educação Ambiental apresenta uma nova dimensão a ser incorporada ao processo educacional, trazendo toda uma recente discussão sobre as questões ambientais, e as consequentes transformações de conhecimento, valores e atitudes de uma nova realidade a ser construída. (GUIMARÃES, 2000, p.9)

A perspectiva ambiental consiste num modo de ver o mundo no qual se evidencia a correta interpretação e compreensão das inter-relações e da interdependência dos diversos elementos na constituição e manutenção da vida (BRASIL, 1998a).

Ao passo que a humanidade aumenta gradativamente o seu potencial de intervir na natureza para satisfazer suas necessidades, surgem tensões e 
conflitos quanto ao uso do espaço e dos recursos (BRASIL, 1998a). Pelo atributo de sua capacidade reflexiva, o homem usa e transforma os recursos da natureza de forma qualitativa e quantitativa diferente dos outros seres vivos, e, ao passo que essas transformações ocorrem rapidamente e em escala sem precedentes, as consequências têm sido catastróficas para o meio ambiente.

A solução dos problemas ambientais é cada vez mais urgente para garantir o futuro da humanidade, e, tanto na dimensão coletiva quanto individual, depende da relação que se estabelece entre sociedade/natureza (BRASIL, 1998a).

Segundo Oliveira (2000) para o tratamento da questão ambiental nos processos educacionais é fundamental considerar a interação homem - meio ambiente como elemento de caracterização das relações sociedade natureza.

De acordo com Silva e Grillo (2008), observa-se a ausência da consciência ecológica na sociedade atual. Assim sendo, é de extrema necessidade a Educação Ambiental uma vez que ela pode contribuir significativamente para a formação de cidadãos conscientes e aptos a decidirem e atuarem na sua realidade, comprometidos com a proteção e preservação do meio ambiente.

Os Parâmetros Curriculares Nacionais (PCN's) incluem a Educação Ambiental como tema transversal a ser trabalhado nas diversas áreas do conhecimento. A transversalidade no currículo escolar prioriza e contextualiza a investigação das realidades locais e regionais na abordagem de questões referentes ao meio ambiente. Dessa maneira, é possível que se institua, na prática educativa, uma analogia entre o "aprender sobre a realidade" por meio de conhecimentos teoricamente sistematizados, e o "aprender na realidade e da realidade", com o emprego de questões da vida real e de sua transformação (BRASIL, 1998a). Nesta dialógica:

A Educação Ambiental (EA) além de permear toda prática educacional na busca de uma ação reflexiva e crítica da realidade, também deve, como tema transversal, possibilitar a opção por diferentes situações desejadas, como responsabilidade, cooperação, solidariedade e respeito pela vida. Dentro de uma visão construtivista interdisciplinar do conhecimento, a EA visa a consolidação da cidadania a partir de conteúdos vinculados ao cotidiano e aos interesses da maioria da população. (LUCAS; TIMM; GOMES, 2010, p.1470)

O conhecimento escolar não deve ser alheio ao debate ambiental da comunidade, ao contrário, deve possibilitar ao aluno participar, interagir, integrar, refletir e manifestar-se, no processo de convívio democrático e participação social (BRASIL, 1998b). 
A escola é o espaço social onde o aluno será sensibilizado para as ações ambientais e fora do âmbito escolar ele será capaz de dar sequência ao seu processo de socialização. Comportamentos ambientalmente corretos devem ser aprendidos na prática, no cotidiano da vida escolar, contribuindo para a formação de cidadãos responsáveis.

Ao refletir sobre o papel da escola como espaço para a formação cidadã e construção do conhecimento, e, na expectativa de propiciar ao aluno uma visão multidisciplinar em relação aos problemas e questões ambientais, os PCN's salientam que:

[...] será por meio de diferentes temas de trabalho que a escola poderá propor informações e conceitos científicos, buscando crescente entendimento pelo aluno das relações entre os componentes dos ambientes, especialmente com o ser humano, essenciais para a interpretação de problemas e questões ambientais. Tanto os conhecimentos das Ciências Naturais como as informações sobre a sociedade e a cultura têm lugar na construção destes conhecimentos pelo estudante. Uma melhor compreensão dos ambientes local e regional é uma meta permanente de Ciências Naturais. (BRASIL, 1998b, p.43)

Segundo o Programa Nacional de Educação Ambiental (Pronea), para a edificação de sociedades sustentáveis as estratégias de enfrentamento da problemática ambiental devem articular esforços entre todos os tipos de intervenção ambiental direta, incluindo-se, portanto, ações em Educação Ambiental. Desse modo, "assim como as medidas políticas, jurídicas, técnicocientíficas, institucionais e econômicas voltadas à proteção, recuperação e melhoria socioambiental' (BRASIL, 2005, p.17), também são de extrema importância atividades no âmbito educativo.

Esta preocupação está expressa nos Parâmetros Curriculares Nacionais para o Ensino Fundamental ao considerar que:

A presença dos problemas ambientais nos meios de comunicação alerta as pessoas, mas não lhes assegura informações e conceitos científicos sobre o tema. Exemplo disso é o emprego de ecologia como sinônimo de meio ambiente e a difusão de visões distorcidas sobre a questão ambiental. É função da escola a revisão dos conhecimentos, sua valorização e enriquecimento. A questão ambiental, envolvendo aspectos econômicos, políticos, sociais e históricos, acarreta discussões sobre responsabilidades humanas voltadas ao bem-estar comum e ao desenvolvimento. Interessa a todas as áreas do ensino fundamental, e é tratada de forma abrangente pelo tema transversal Meio Ambiente. (BRASIL, 1998b, p.41) 
Nesta dialógica, o educador assume importante papel ao atuar como coordenador de atividades integradas dentro da sala de aula, liderando, monitorando e incentivando a percepção, a criatividade, a análise crítica das causas e consequências ambientais e as sugestões de soluções.

Para auxiliar os professores no que compete ao trabalho voltado para a Educação Ambiental, o Conteúdo Básico Comum de ciências para o ensino fundamental de Minas Gerais (MINAS GERAIS, 2005) sugere 0 desenvolvimento de alguns temas complementares.

O eixo temático I "Diversidade da Vida", em seu tema 1 "Diversidade da Vida nos Ambientes" aponta como uma sugestão de tema complementar que os professores trabalhem os impactos ambientais e extinção das espécies, com vistas a desenvolver no aluno a habilidade de interpretar informações de diferentes fontes sobre transformações ambientais provocadas pela ação humana e o risco de extinção de espécies (MINAS GERAIS, 2005, p.55). O tema 2 "Diversidade dos Materiais" que também compõe o eixo temático I, sugere como tema complementar a reciclagem e preservação ambiental para que os alunos sejam capazes de compreender a íntima relação entre reciclagem e preservação ambiental (MINAS GERAIS, 2005, p.56).

Uma análise histórica demonstra que a prática da Educação Ambiental já é regulamentada no Brasil pela Lei 9.795 (BRASIL, 1999) que formaliza em alguns de seus artigos:

Art. 1ํ. Entendem-se por Educação Ambiental os processos por meio dos quais o indivíduo e a coletividade constroem valores sociais, conhecimentos, habilidades, atitudes e competências voltadas para a conservação do meio ambiente, bem do uso comum do povo, essencial à sadia qualidade de vida e sua sustentabilidade.

Art. 2‥ A Educação Ambiental é um componente essencial e permanente da educação nacional, devendo estar presente, de forma articulada, em todos os níveis e modalidades do processo educativo em caráter formal e não-formal.

Diante o exposto, desenvolvemos uma proposta que visava elaborar, construir e avaliar um jogo didático de tabuleiro que auxiliasse na sensibilização, compreensão e posicionamento dos alunos frente as questões ambientais, de modo a desenvolver a consciência ambiental e levando a interações construtivas, justas e ambientalmente sustentáveis, abordando os temas Diversidade da Vida nos Ambientes e Diversidade dos Materiais. 


\section{Metodologia e elaboração do jogo}

A princípio foi feito um levantamento bibliográfico a respeito do uso de jogos na educação a partir das informações disponibilizadas em livros, periódicos, sites, documentos oficiais e artigos da base de dados SCIELO e CIÊNCIA \& EDUCAÇÃO utilizando os termos: jogos, jogos didáticos, jogos infantis, jogo na educação. Posteriormente foi feita uma seleção mais criteriosa, que culminou na escolha daqueles que fundamentaram a construção do jogo e elaboração deste artigo.

Para a construção do jogo foi necessário domínio do conteúdo a ser trabalhado e o auxílio de um professor-orientador no assunto. Foi dado enfoque especial às questões e problemas ambientais do nosso tempo, envolvendo aspectos relacionados à quebra do equilíbrio ambiental pelas ações do homem. Como ponto de partida foi confeccionado um tabuleiro em cartolina branca simulando o percurso de um rio e este foi subdividido num total de cinquenta casas. Também foram feitos cartões, denominados "cartelas ecológicas", contendo perguntas sobre questões ambientais, ecologia e impacto das atividades humanas no ambiente. As perguntas do jogo foram redigidas em computador e impressas em papel sulfite, sendo posteriormente recortadas e coladas em papel cartão.

O jogo foi intitulado "TRILHA DAS ÁGUAS: O MEIO AMBIENTE EM FOCO”. Ele é composto por um tabuleiro (Figura 1) e pelas cartelas ecológicas (Figuras 2, 3 e 4), que contêm perguntas a serem respondidas. Também é utilizado um dado de seis faces para o sorteio do número de casas que se deve avançar, pinos para marcar a posição das equipes no tabuleiro e uma ampulheta para cronometrar o tempo de resposta.

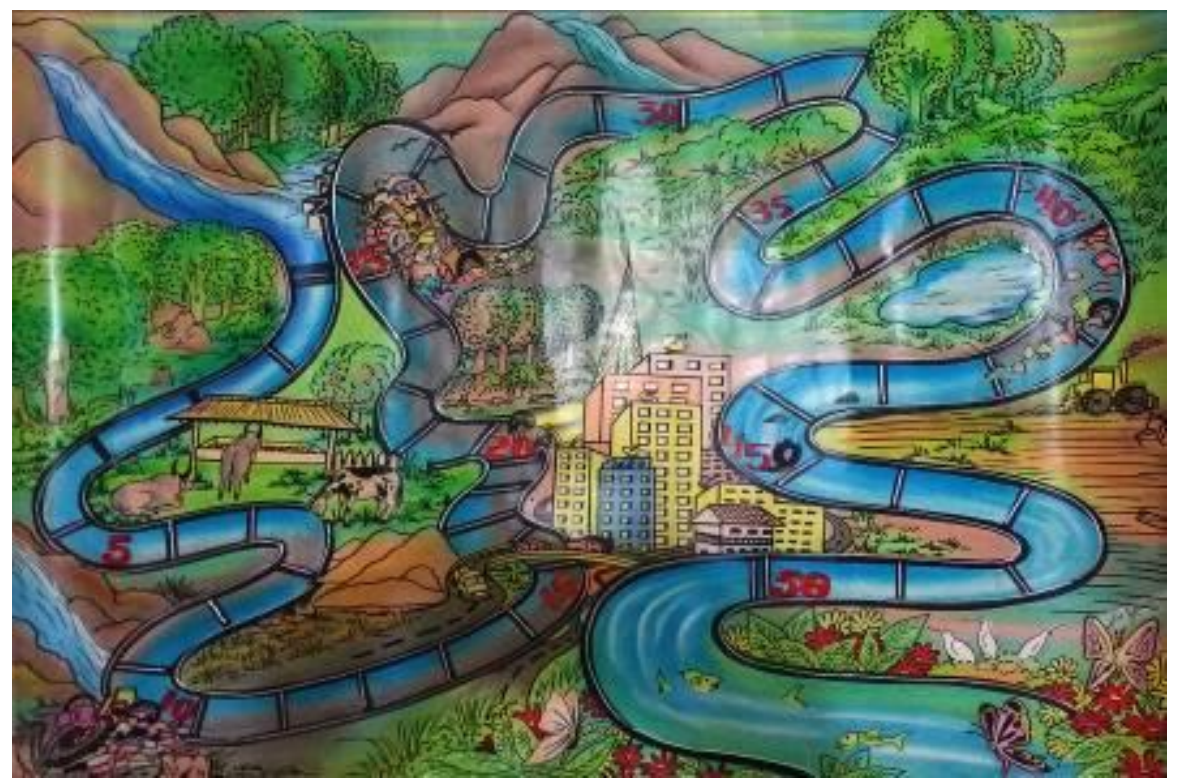

Figura 1: Fotografia do tabuleiro do jogo.

Fonte: Elaborado pelo autor. 


\section{TRILHA DAS ÁGUAS: O MEIO AMBIENTE EM FOCO}

“Embora ninguém possa voltar atrás e fazer um novo começo, qualquer um pode começar agora e fazer um novo fim."

(Chico Xavier)

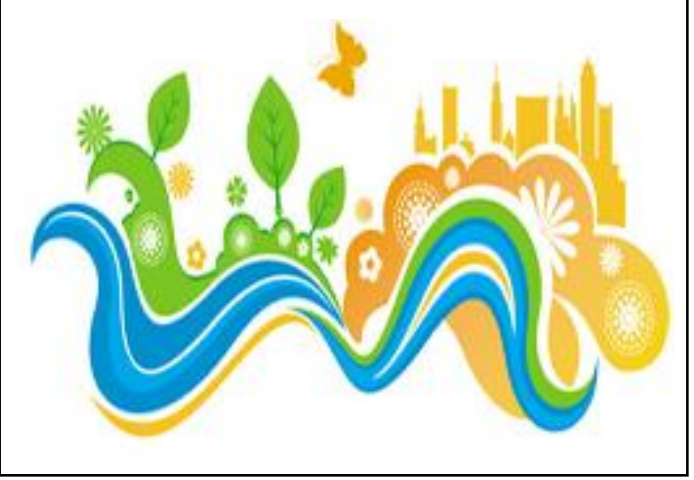

Figura 2: Frente das cartelas ecológicas. Fonte: Elaborada pelo autor.
Se todas as árvores de uma floresta fossem derrubadas para a construção de várias casas para a população poderíamos considerar que:

a) Isso não traria prejuízos para os animais que lá vivem.

b) Não haveria nenhum problema desde que a população mais carente fosse beneficiada.

c) Vários animais que vivem na floresta seriam diretamente prejudicados.

d) Seria algo muito bom visto que várias pessoas não possuem casa própria para morar.

e) O ser humano e os animais que vivem na floresta seriam beneficiados mutuamente.

Em caso de erro, retorne 4 casas.

Figura 3: Modelo de pergunta. Fonte: Elaborada pelo autor.

Figura 4: Modelo de pergunta.

Fonte: Elaborada pelo autor. 


\section{Regras do jogo}

Primeiramente, devem ser formadas equipes compostas por, no máximo, seis alunos. Depois é preciso definir, através do auxílio de um dado de seis faces, a equipe que iniciará o jogo. A ordem das equipes que irão efetuar suas jogadas na sequência leva em consideração o sentido anti-horário. Posteriormente, todas as cartelas ecológicas que compõem o jogo são embaralhadas e colocadas na forma de um monte com a face das perguntas virada para baixo.

Cada cartela ecológica contém uma pergunta a ser respondida, sendo esta lida pelo mediador sempre que alguma equipe chega às casas de números $5,10,15,20,25,30,35,40,45$ e 50 . Na primeira rodada do jogo, uma a uma, cada equipe joga o dado de seis faces e retira uma cartela ecológica do monte. Caso respondam a pergunta corretamente, avançam o número de casas indicadas no dado. Porém, caso a equipe responda errado, deverá retornar o número de casas escrito na própria cartela. Se a resposta estiver incorreta, a equipe poderá retornar algumas casas ou ficar uma rodada sem jogar. As perguntas podem ser de múltipla escolha, com cinco possíveis opções de respostas ou de verdadeiro ou falso.

É importante frisar que, após a retirada da cartela ecológica, a equipe terá um prazo máximo de 2 (dois) minutos para chegar a uma resposta, tempo este que será marcado pela ampulheta.

O mediador é o único responsável pela explicação das regras e leitura das perguntas.

A equipe campeã do jogo será aquela que primeiro chegar à última casa do tabuleiro.

\section{Avaliação do jogo}

O jogo foi avaliado por alunos das séries finais do ensino fundamental de uma escola pública estadual da cidade de Igaratinga-MG após sua utilização pelos mesmos.

Para a coleta de dados foram utilizados questionários adaptados do modelo utilizado por Borges, Aranha e Sabino (2010), em seu trabalho sobre a fotografia de natureza como instrumento para Educação Ambiental.

O tempo gasto pelos alunos para terminar 0 jogo foi de aproximadamente cinquenta minutos, e, depois disso, eles responderam ao questionário, sendo este composto por 10 questões. As três primeiras tinham por objetivo caracterizar os alunos quanto à idade, sexo e série. Três questões relacionadas à temática ambiental com alternativas sim ou não e quatro questões para avaliar parâmetros referentes ao jogo.

A atividade foi realizada em período matutino com as turmas do $6^{\circ}, 7^{\circ}, 8^{\circ}$ e $9^{\circ}$ ano do ensino fundamental. Participaram da avaliação do jogo 142 alunos, 
sendo, quarenta e três do $6^{\circ}$ ano; trinta e seis do $7^{\circ}$ ano; vinte e oito do $8^{\circ}$ ano e trinta e cinco do $9^{\circ}$ ano.

Em relação ao perfil dos alunos que participaram do jogo foram coletados dados sobre idade, sexo e série. Na turma do $6^{\circ}$ ano do ensino fundamental, trinta e nove alunos tinham 11 anos e quatro tinham 15 anos, sendo vinte e sete do sexo feminino e dezesseis do sexo masculino. Na turma do $7^{\circ}$ ano, trinta e um alunos tinham 12 anos e cinco tinham 13 anos, 23 do sexo feminino e 13 do sexo masculino. No $8^{\circ}$ ano vinte e cinco alunos tinham 13 anos e três tinham 14 anos, 16 do sexo feminino e 12 do sexo masculino. Já na turma do $9^{\circ}$ ano trinta e dois alunos tinham 14 anos e três tinham 15 anos, sendo 18 do sexo feminino e 17 do sexo masculino.

\section{Resultados e discussão}

Segundo os dados coletados pelo questionário, ao serem perguntados o que eles acharam do jogo, dos 142 alunos participantes, 109 assinalaram a alternativa "muito divertido"; 26 alunos assinalaram "legal" e 7 assinalaram "bom". Nenhum dos alunos participantes achou o jogo cansativo, demorado ou ruim.

O método utilizado neste estudo - observação dos acertos em questões relacionadas à temática ambiental - se mostrou eficiente, pois permitiu verificar se realmente os alunos aprenderam algo com o jogo. Este método foi escolhido porque permite uma avaliação rápida e eficaz do aprendizado pelo jogo.

Os resultados das respostas às questões apresentadas aos alunos nos questionários estão na Tabela 1, onde "N" representa o número de alunos que participaram do jogo. Observa-se que houve elevado nível de acerto nas três questões.

Tabela 1: Número de alunos e porcentagem de acerto nas respostas às questões apresentadas pelo questionário após o jogo "Trilha das águas: o meio ambiente em foco".

\begin{tabular}{|c|c|}
\hline QUESTÕES & $\begin{array}{l}\text { RESPOSTAS } \\
\quad N=142\end{array}$ \\
\hline $\begin{array}{l}\text { Se as árvores de uma floresta forem } \\
\text { derrubadas para a construção de várias } \\
\text { indústrias, isso afetaria os animais que nela } \\
\text { vivem? }\end{array}$ & SIM $129(90,85 \%)$ / NÃO 13 (9,15\%) \\
\hline $\begin{array}{l}\text { O homem é o principal causador de danos ao } \\
\text { meio ambiente, como o aumento do efeito } \\
\text { estufa, a destruição da camada de ozônio e a } \\
\text { poluição da água, solo e ar. }\end{array}$ & SIM 139 (97,89\%) / NÃO 3 (2,11\%) \\
\hline $\begin{array}{l}\text { A natureza nos fornece vários recursos e } \\
\text { estes podem ser utilizados, por exemplo, } \\
\text { para a produção de roupas, combustíveis, } \\
\text { medicamentos e vacinas. }\end{array}$ & SIM 131 (92,25\%) / NÃO 11 (7,75\%) \\
\hline
\end{tabular}

Fonte: Dados coletados pelo autor.

Revbea, São Paulo, V. 11, № 5: 167-183, 2016. 
Outros parâmetros avaliados foram:

a) Opinião dos alunos sobre o aprendizado pelo jogo - pelas respostas, verificou-se que somente nove (6,33\%) dos 142 alunos participantes, responderam que o jogo não havia ensinado algo que eles já não sabiam antes.

b) Opinião da professora sobre o uso do jogo para trabalhar a Educação Ambiental - a professora acredita que o jogo é uma excelente estratégia para abordagem de assuntos relacionados à temática ambiental. Elas destacaram que o jogo auxilia no ensino potencializando a aprendizagem dos educandos de forma prazerosa e divertida.

c) Quanto à linguagem utilizada nas perguntas e explicação das regras no que se refere à linguagem utilizada nas perguntas que compõem o jogo e explicação das regras, 136 alunos (95,77\%) avaliaram como adequada e de fácil entendimento, indicando que está coerente e que permite a compreensão e entendimento a respeito dos conteúdos abordados. Apenas seis alunos $(4,23 \%)$ consideraram não adequada e, por vezes, confusa.

d) Importância do trabalho em grupo - também foi perguntado aos alunos participantes o que eles acharam da prática do jogo em grupo. Com exceção de doze alunos $(8,45 \%)$, os demais $(91,55 \%)$ disseram ter gostado de trabalhar em grupo, justificado pela possibilidade de interação e discussão, importância de um auxiliar o outro, chegar às conclusões com maior agilidade, escutar a opinião do outro e divertimento, o que atua de modo a aproximar professor e alunos e os alunos entre si, ao passo que facilita o aprendizado. As duas professoras também perceberam a importância do trabalho em grupo, uma vez que essa integração estimula o aprendizado dos alunos por permitir a troca mútua de conhecimentos.

Averiguando os resultados obtidos foi possível perceber que alunos e professoras gostaram do jogo, os alunos aprenderam sobre questões relacionadas à temática ambiental, foram sensibilizados e estimulados pelo jogo, uma vez que, quando o jogo foi apresentado, chamou a atenção de todos, despertando curiosidade e interesse. Além disso, durante sua aplicação, verificou-se o entusiasmo e empenho deles na tentativa de chegar às respostas corretas.

Outro aspecto relevante, observado durante a aplicação do jogo, foi o desenvolvimento de habilidades do trabalho em equipe e da comunicação.

\section{Conclusões}

A proposta de um jogo de tabuleiro e sua função educativa foi facilmente observada durante a aplicação com os alunos, verificando-se que auxilia os professores na prática da Educação Ambiental, favorecendo a sensibilização e permitindo aos alunos reavaliar seu posicionamento frente às questões ambientais, em clima de alegria, descontração e prazer. O jogo possibilitou aos 
alunos a familiarização com questões relevantes acerca da temática ambiental, como poluição do ar, água e solo, desmatamentos, queimadas, impactos das atividades humanas no ambiente, entre outras.

Por combinar aspectos lúdicos aos cognitivos, entende-se que o jogo é um importante instrumento para trabalhar a Educação Ambiental na escola, uma vez que, além de permitir ao aluno tornar-se sujeito construtor de seu próprio conhecimento, promove a sensibilização e posicionamento em relação aos problemas ambientais, potencializando a mudança de atitudes e construção de valores ambientalmente corretos.

Pelo exposto, entende-se que o uso de jogos para trabalhar a Educação Ambiental na escola é uma proposta relevante e viável, pois este material, quando bem preparado e estruturado, permite ao aluno construir seu próprio conhecimento num trabalho voltado para a coletividade, socialização de conhecimentos prévios e sua utilização para a edificação de conhecimentos novos e mais complexos. Espera-se que o jogo também tenha contribuído para sensibilizar e conscientizar os professores em relação à importância desse material, estimulando sua incorporação na prática pedagógica e a elaboração de outros jogos para o ensino de diferentes temas.

\section{Agradecimentos}

A todos os Biólogos e docentes que, com muita dificuldade, amor, entusiasmo e perseverança, contribuem para a melhoria da qualidade do ensino no Brasil, principalmente no que diz respeito à Educação Ambiental.

\section{Referências}

ARNONI, M.E.B. et al. Metodologia da mediação dialética e abordagem da temática ambiental em uma perspectiva interdisciplinar: letras e ciências biológicas. In: Livro Eletrônico dos Núcleos de Ensino da Unesp - Edição $2006 . \quad$ p.770-780. Disponível em: <http://www.unesp.br/prograd/PDFNE2004/artigos/eixo10/metodologiadamedia caodialetica.pdf >. Acesso em: $06 \mathrm{dez} .2016$.

BORGES, M.D.; ARANHA, J.M.; SABINO, J. A fotografia de natureza como instrumento para Educação Ambiental. Ciênc. educ. (Bauru), Bauru, v. 16, n. 1, $2010 . \quad$ Disponível em: $<$ http://www.scielo.br/scielo.php?script=sci arttext\&pid=S151673132010000100009\&lng=pt\&nrm=iso >. Acesso em: 06 dez. 2016.

BRASIL. Lei Federal 9.795, de 27 de abril de 1999. Dispõe sobre a Educação Ambiental, institui a Política Nacional de Educação Ambiental e dá outras providências. Diário Oficial da República Federativa do Brasil, Brasília, DF, 28 de abril $1999 . \quad$ Disponível em: <http://www.planalto.gov.br/ccivil 03/Leis/L9795.htm>. Acesso em: 06/12/2016. 
BRASIL. Parâmetros curriculares nacionais: terceiro e quarto ciclos: apresentação dos temas transversais. Secretaria de Educação Fundamental. Brasília: MEC/SEF, 1998a. 436 p. Disponível em: $<$ http://portal.mec.gov.br/seb/arquivos/pdf/ttransversais.pdf>. Acesso em: 06/12/2016.

BRASIL. Parâmetros curriculares nacionais: terceiro e quarto ciclos do ensino fundamental: Ciências Naturais. Secretaria de Educação Fundamental. Brasília: MEC/SEF, 1998b. 138p. Disponível em: $<$ http://portal.mec.gov.br/seb/arquivos/pdf/ciencias.pdf>. Acesso em: 06/12/2016.

BRASIL. Programa nacional de Educação Ambiental - ProNEA / Ministério do Meio Ambiente, Diretoria de Educação Ambiental; Ministério da Educação. Coordenação Geral de Educação Ambiental. - 3. ed - Brasília: Ministério do Meio Ambiente, 2005. 102p. Disponível em: $<$ http://portal.mec.gov.br/secad/arquivos/pdf/educacaoambiental/pronea3.pdf>. Acesso em: 06 dez. 2016.

BRASIL. Secretaria de Educação Média e Tecnológica. PCN+ Ensino Médio: orientações educacionais complementares aos Parâmetros Curriculares Nacionais. Ciências da Natureza, Matemática e suas Tecnologias. Brasília: MEC, SEMTEC, 2002. Disponível em: $<$ http://portal.mec.gov.br/seb/arquivos/pdf/CienciasNatureza.pdf>. Acesso em: 06/12/2016.

CAMPOS, L.M.L.; BORTOLOTO, T M.; FELICIO, A.K.C. A produção de jogos didáticos para o ensino de Ciências e Biologia: uma proposta para favorecer a aprendizagem. Caderno dos Núcleos de Ensino, p. 47-60, 2003. Disponível em: $\quad<$ http://www.unesp.br/prograd/PDFNE2002/aproducaodejogos.pdf>. Acesso em: 06/12/2016.

CUNHA, N. Brinquedo, desafio e descoberta. Rio de Janeiro: FAE. 1988.

DOHME, V. Atividades lúdicas na educação: o caminho de tijolos amarelos do aprendizado. Petrópolis, RJ: Vozes, 2003.

GOMES, R.R.; FRIEDRICH, M. A contribuição dos jogos didáticos na aprendizagem de conteúdos de Ciências e Biologia. In: EREBIO, 1., 2001, Rio de Janeiro. Anais... Rio de Janeiro, 2001, p. 389-392.

GUIMARÃES, M. A dimensão ambiental na educação. Campinas: Papirus, 2000.

KISHIMOTO, T.M. Jogo, brinquedo, brincadeira e a educação. Cortez, São Paulo, 1996. 
LUCAS, R.E.A.; TIMM, C.R.F.; GOMES, M.C. O meio ambiente: tema transversal. II Congresso Brasileiro de Agroecologia. Revista Brasileira de Agroecologia. vol. 2. n. 1, 2007, Rio de Janeiro. Resumos... Rio de Janeiro. 2007, p. 1470-1474. Disponível em: <http://www.abaagroecologia.org.br/revistas/index.php/rbagroecologia/article/viewFile/6582/488 7>. Acesso em: 06/12/2016.

MALUF, A.C.M. Atividades lúdicas como estratégias de ensino aprendizagem. Psicopedagogia Online, 2006.

MARCELLINO, N.C. Pedagogia da animação. Campinas, São Paulo Papirus; 1989.

MARPICA, N.S.; LOGAREZZI, A.J.M. Um panorama das pesquisas sobre livro didático e Educação Ambiental. Ciênc. educ. (Bauru), Bauru, v. 16, n. 1, 2010. Disponível em: <http://www.scielo.br/scielo.php?script=sci arttext\&pid=S151673132010000100007\&lng=pt\&nrm=iso > . Acesso em: 06/12/2016. .

MINAS GERAIS (Estado). Secretaria de Estado da Educação de Minas Gerais. Conteúdo Básico Comum - Ciências (2005). Educação Básica - Ensino Fundamental $\left(6^{\underline{a}} \quad\right.$ a $\quad 9^{a}$ série $)$ Disponível em: <http://crv.educacao.mg.gov.br/sistema crv/banco objetos crv/\%7BBC26290C -C90B-44EF-866A-10C750F63D7B\%7D livro\%20de\%20ciencias.pdf>. Acesso em: 06/12/2016.

MIRANDA, S. No Fascínio do jogo, a alegria de aprender. In: Ciência Hoje, v. 28, n. 168. Jan/Fev. 2001 p. 64-66.

OLIVEIRA, E.M. Educação Ambiental uma possível abordagem. Brasília: IBAMA, 2000.

PEDROSO, C.V. Jogos didáticos no ensino de biologia: uma proposta metodológica baseada em módulo didático. In: IX CONGRESSO NACIONAL DE EDUCAÇÃO (EDUCERE), 9., 2009, Curitiba. Anais... Curitiba: PUCPR, 2009, p. 3183-3184. 1 CD-ROM. Disponível em: <http://www.pucpr.br/eventos/educere/educere2009/anais/pdf/2944 1408.pdf>. Acesso em: 06/12/2016.

REIGOTA, M. Desafios à Educação Ambiental escolar. In: JACOBI, P. et al. (orgs.). Educação, meio ambiente e cidadania: reflexões e experiências. São Paulo: Secretaria de Meio Ambiente, 1998. p. 43-50.

SANMARTÍ, N. Didáctica de las ciencias en la educación secundaria obligatoria. Madrid: Síntesis, 2002.

SILVA, D.M.C.; GRILLO, M. A utilização de jogos educativos como instrumento de Educação Ambiental: o caso Reserva Ecológica de Gurjaú (PE). Contrapontos: revista do Programa de Pós-Graduação em Educação da Univali. Santa Catarina, v. 8, n. 2, p. 229-238, 2008. Disponível em: $<$ http://www6.univali.br/seer/index.php/rc/article/viewFile/949/805>. Acesso em: $06 / 12 / 2016$. 
SILVA, L.F.; CARVALHO, L.M. A temática ambiental e o ensino de física na escola média: algumas possibilidades de desenvolver o tema produção de energia elétrica em larga escala em uma situação de ensino. Revista Brasileira de Ensino de Física: São Paulo, v. 24, n. 3, p. 342-352, set. 2002. Disponível em: <http://www.scielo.br/pdf/rbef/v24n3/a12v24n3.pdf >. Acesso em: 06/12/2016.

\section{Anexo}

\section{Questionário que foi respondido pelos alunos após a aplicação do jogo didático.}

1) Qual a sua idade?

2) Marque com um X o seu sexo: ( ) Feminino ( ) Masculino

3) Em que série você está? Marque a opção com um X.

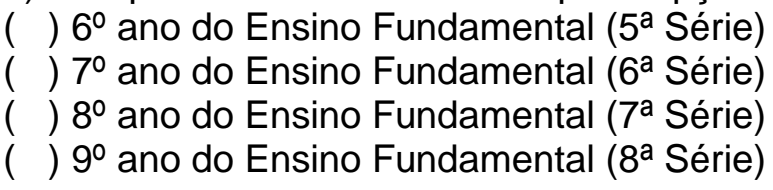

4) Leia atentamente a pergunta e marque um $X$ na opção desejada: Se as árvores de uma floresta forem derrubadas para a construção de várias indústrias, isso afetaria os animais que nela vivem? ( ) SIM ( ) NÃO

5) Leia atentamente a afirmativa e marque um $X$ na opção desejada: $O$ homem é o principal causador de danos ao meio ambiente, como o aumento do efeito estufa, a destruição da camada de ozônio e a poluição da água, solo e ar. ( ) SIM （）NÃO

6) Leia atentamente a afirmativa e marque um $X$ na opção desejada: $A$ natureza nos fornece vários recursos e estes podem ser utilizados, por exemplo, para a produção de roupas, combustíveis, medicamentos e vacinas. ( ) SIM （）NÃO

7) Marque apenas uma das opções abaixo com um $X$ para expressar o que você achou do jogo "TRILHA DAS ÁGUAS: O MEIO AMBIENTE EM FOCO":

( ) Muito divertido ( ) Legal ( ) Bom

( ) Cansativo ( ) Demorado ( ) Ruim

8) Quando à linguagem utilizada nas perguntas e explicação das regras do jogo você considera que:

( ) Foi adequada e de fácil entendimento

( ) Não foi adequada, sendo, por vezes, confusa

9) Você gostou da prática do jogo em grupo? ( ) SIM （）NÃO

10) Você aprendeu algo que ainda não sabia com o jogo? （） SIM （） NÃO 